\title{
Design and Manufacturing of The Device of Immediate Three Dimensional Report to Measure The mechanical force of The hook Punch
}

"Dr/ KhaledAbd- El mawgoudAbd- Elazeem

Introduction and problem of the research:

The scientific trace of the definition of the kinesthetic Performance nowadays and in the past clarifies to us the huge difference between the skills' standard which the sportsmen have in the past to achieve a specific goal and the development of these skills which reflected directly on the levels which the sportsmen achieved in all kinds of sports. This development is due to the sufficient understanding of the mechanic principles related to the activity of the player which is one of the infrastructures in the success of performance development's methods. $(2: 1)$ In the past, the activity was noticed through seeing it to determine the strength and weakness points in its path, but the need to use the developed scientific devices is inevitable to the scientific diagnosis as these devices can sort and classify the information to its basic elements and then handle it rationally and statistically to summarize it in a digital result acceptable to comparison with a specific standard and convert it from its chemical formulas to a result with a useful meaning. $(2: 1)$

The workers in the Biomechanic field are using the suitable methods of evaluation to study the mechanic movements which the man performs with attention to the features of these movements and the possibility to determine the mechanical reasons and the bio-dynamic features of the sport skills.(1 : 134-135)

Every

skilful performance has specific features whether it was kinetic or kinematic to perform the skill easily and without a great effort to obtain the highest degree of effect. The most important kinetic feature of the punches in the boxing sport is the power.

Boxing sport has basic demands and capabilities as its technical moves are

${ }^{*}$ Lecturer in Department of athletic Training and Movement Sciences Faculty of Physical Education

Assiut Journal For Sport Science Arts 
characterized by the dynamic harmonize with its power, speedand accuracy. Punches are considered as one of the technical and tactical moves of the boxer. $(6: 1)$

Because of the variety of levels which the boxer go through it and had to deal with different types of competitors' bodies and different situations which may make him lose the match if he can't confront it. $(4: 183)$

One of these situations is when the boxer plays against a tall boxer and he must punch him through medium and short distances so it is very important to use the short range punches specifically the hook punches.

\section{Research problem:}

Everything we know about the universe and all its rules are the result of gauging method. The famous scientist "Kelvin" said "When you are able to measure what $\mathrm{u}$ are talking about and turning it to numbers, so you have now information about it, but when you are not able to convert it to numbers so your knowledge is not sufficient but you can consider it as a beginning".(7 : 1)
From the perspective of the vital mechanic to the law of force and how to invest it in the sports field to produce a high outcome of force, the researcher noticed that boxing sport has a little of the scientific instruments to measure the force of the side punch which considers as the most important mechanical principles to evaluate the punch. It is clear now that the need to a measurement method is an inevitable thing which can introduce an objective help. To study this variable, we should know its Characteristics such as the amount, the direction and the impact point. In the light of this knowledge we can determine Stresses and agitations resulting from these forces to choose the suitable material to each part of the device which can handle ale the effective forces without any damage to the engineered parts which will receive the force of the punch.

In the Mechanics science, the force is measured by two ways: the first is the indirect measurement which calculate the distance covered by the object in a specific time or the speed of the object. The second way is the direct 
measurement which depends on the balance of the forces whether it was a mechanical balance or hydraulic balance or any other ways depend onmeasuring the pressure of the force on the objects. These kinds of devices depend on the rule of the amplification of objects' bending or the prolongation of the metal part.(3 : 256-290)

The researcher in this research will depend on measuring the pressure of the force on the objects with determining the places of great value of forces in which he will stabilize the sensors.

To all these reasons, the of this device is one of the most important scientific devices which will be established on mechanical basics and physical titration with a high degree of accuracy so we can depend on this device to determine the power of the three Dimensional side punch through immediate report which will enable taking of an objective decision about the physical case of the player from a mechanic perspective. The other important thing to the researcher will be the choice of the quality of the facilities in accordance to the cheap financial cost requirements of the research with attention to stability and simplicity of the process and also to the compensability of the device's transfer in the case of need. Also there will be a possibility to make calibration with every measurement to prove the device's credibility.

\section{The importance of the} research:

We can say that the implementation of this device will achieve the researcher's goals like:

- Measurement the strength of the punch with attention to the technical features of the hook punch.

- $\quad$ The result of the device is more accurate and objective than the other traditional tests.

- Relevance of the device to the trainer especially the absence of any external wired connections.

- Measurement of the time from the less point of the side punch's power to the highest point.

- Sensitivity of the used sensors to start from the lowest value $(200 \mathrm{gm})$ to the highest value $(400 \mathrm{~kg})$.

- Easy interaction with scholars through an efficient 
design of the program's interfaces and saving data.

- $\quad$ The cheap financial cost compared to the current system.

\section{Aimof the research:}

The research aims to manufacture and design the equipment of immediate three dimensional report to measure the power of the hook punch.

\section{Questions of the research:}

- Is it possible to measure the three elements of the mechanical power of the hook punch in the light of the engineered design?

- Is it possible to capture the electric signal wirelessly and convert it to legible digital values?

- Is there any difference with statistical indication between the averages of the three attempts of every person in the value of the hook punch's power?

- Is there any difference with statistical indication between the averages of the different types of weight in the value of the hook punch's power?

\section{Research procedures:}

Research approach:

The researcher used the descriptive method because of its adequate to the nature of the research.

\section{Research sample:}

The choice of the research sample depends on the deliberate way by choosing light, average, above average, heavy and super heavy to determine the differences between their punches' power through three attempts to each one of them which means (15) attempts.

\section{Data collection tools:}

- Engineering Drawing Program (solid work)

- $\quad$ Metal ball weighs (7.265

$\mathrm{kg})$

- $1 \mathrm{~m}$ wire

- Medical scale

- The calibration of the electrical signal equipment.

The scientific basis of the equipment:

Process of designing any device or machine to perform specific function includes many stages, first of all is the description of the problem which means the accurate description of the effective powers its direction and points of pressure and then determining Stresses and agitations resulting from these forces to choose the suitable material to each part of the device which can handle ale 
the effective forces without any damage to the engineered parts. $(5: 5-6)$

So the scientific basis of the device depends on the three dimensional measurement of the hook punch's power which considers one of the most basic variables in the boxing sport. To measure these forces 3 dynamometers were used and disturbed on the three orthogonal cores. Every dynamometer has a flexible loop made of alloy steel (steel resistant to rust) to ensure the high natural frequency and resistance of rust to make a high thermal connection. On the surface of the ring there are 2 heat measures since the external effort fit with the heat in the ring which is a result of change in the effective powers' values. The heat measures were fixed in the places of the great value to concentrate the effort on the loop to ensure accuracy of reading the measures and also to ensure stability in the different temperature degrees and humidity. Then the data of the heat measure is delivered through a data conversion card which works with "windows" and connected to PC. The device was tested under different endure values and produced satisfying results.

\section{Parts of the device sand its} geometrical dimensions:

The parts of the equipment will be clarified in the form of items containing the framework of the idea of the equipment:

The first element: equipment structure

The equipment is created from metal parts, mechanical and electrical parts form (1). The framework of the device contained squared basis $(40 \times 40 \mathrm{~cm})$ made of iron sheet with $(1 \mathrm{~cm})$ thick and rectangular pole which is fixed on the squared basis. The rectangular pole is $(160 \mathrm{~cm})$ long and made of iron sheet with $1 \mathrm{~cm}$ thick, it is also recessed from inside as another pole of $50 \mathrm{~cm}$ long and $(16 \times 16)$ thick is through it. The second pole must has free movement inside the first pole. Also a group of boards made of iron sheet and with $(1 \mathrm{~cm})$ thick are fixed on the second pole 
but it has different has a ball on one side and measurements. The device a pin on the other. Form also has 6 poles; each pole

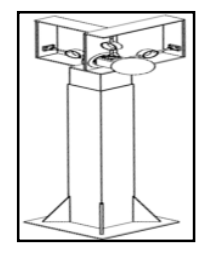

\section{Form (1)}

\section{The second element: load cell}

It consists of loops with specific dimensions form

dimensions determined (3).

These were through geometrical equations and by these equations the accurate dimensions which fit with the device were determined. The external bore is $(8 \mathrm{~cm})$ and the internal bore is $(7.7 \mathrm{~cm})$. The thickness of the loop is $(3 \mathrm{~mm})$ and the width of the loop is $(3 \mathrm{~cm})$, every loop has two opposite holes, the bore of the hole is $(5 \mathrm{~mm})$. The loops are made of iron. These measurements make the loop endure a power up to $(75$ $\mathrm{kg})$.

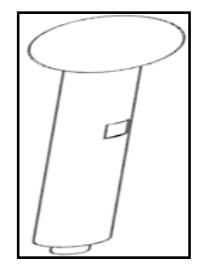

Form (2)

\section{The Third Element: Sensors (Strain Gauge):}

These sensors are power of the punch. The fixed above the three loops player punches the ball (Load cell) and its then the power of the function is to measure the__ punch transfers to the Assiut Journal For Sport Science Arts 
loops directly and the sensors starts in the value sensors sense it form (4). of (100

The sensitivity of the

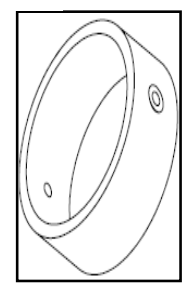

Form (3)

\section{The Forth Element: Amplifier}

The amplifier (form

5 ) is made of a group of electrical resistances: 5 (105 SMD), 5 (501 SMD) , 10 (102 SMD) , 10 (201 SMD) , 15 (103 SMD) , 5 (POT 5K). The function of the amplifier is to amplify the signal which comes from the Strain gauge. There are three amplifiers in the device each one of them is connected to a loop in the load cell.

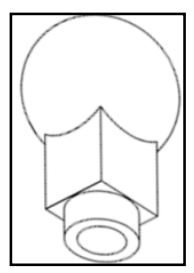

Form (4)

\section{The Fifth Element: The Wooden Punch Ball}

It is a ball made of wood to endure the punches and it is also coned with $(10 \mathrm{~cm})$ bore and with $(1 \mathrm{~cm})$ hole. Inside this hole, there is a screw pass through the upper side to the lower side to fix the ball (form
6). To be like a human body, the ball was covered by a layer of sponge with $(2.5 \mathrm{~cm})$ thick and to tight the sponge layer it was covered by a layer of leather to cover the ball completely. 


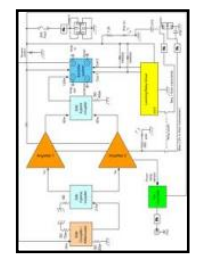

\section{Form (5)}

\section{The sixth element: Data causation}

It receives the analog signal from the amplifier and converts it to digital signals and then transfers these signals to legible values which can be explained and evaluated by specific program (form 7).

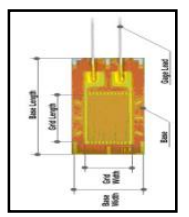

Form (6)

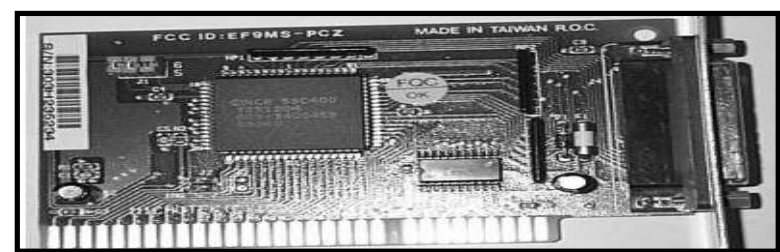

\section{form 7}

\section{The seventh element: Software}

This program consists of a group of interfaces in which the required data of the person are written. These interfaces are:

- An interface contains the password to open the program form(8).

- An interface in which the special date of the player are written like (name- height- weight- birth date- number of the training years- type of the measurement).

- An interface with the special curves of every skill on the three axes (X.Y.Z).

An interface with a report of the measured skill. The report consists of the date which were entered before and a form (9) under this data with the values 
of the power on every axis digitally and another chart shows the shape of the power's

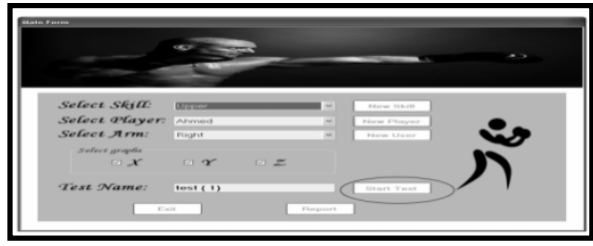

Form (8) curve at the moment of punch and at the moment of stopping.

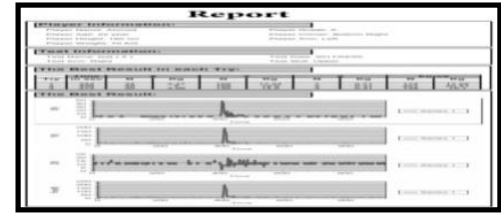

form (9)

\section{The eighth element: Operation method}

First, press the "power" button of the computer, then open the program on the desktop, insert all the boxer's data (Height, Weight, Age, Date of Birth, Measurement Type, Skill Name), and then open the results page (Main page), and let the player performs the side punch to the ball (which is fixed to the device) and the immediate value of the punch's power will be shown on the three axes (X.Y.Z). After that the boxer will perform three attempts which will be recorded to choose the best one of them. We can also find the total force in the three-dimensional immediate report and then save the report in Excel or PDF format.

\section{Scientific calibration of the equipment:}

Calibration of measurement equipment is one of the most important concepts which the scientific measurement is based on, since the measurement process does not consider in an accurate way- which meets the requirements of quality in the time of globalization and sharp competition between countriesunless the measurement result was attached with identification of the chance of mistake in the designed equipment and this will be through the measurements process which guarantee the device authority within the accurate calibration processes of the equipment. The researcher made the calibration of this equipment according to the following way:

Hanging a $1 \mathrm{~m}$ wire to guarantee lack of extensibility, 
a metal ball hanged to the end of the wire and the other side hanged to the cell, determining the punch's power from 200 gm up to 2000 gm (form 10) according to the lowest value which the sensors can measure.

The wall ceiling

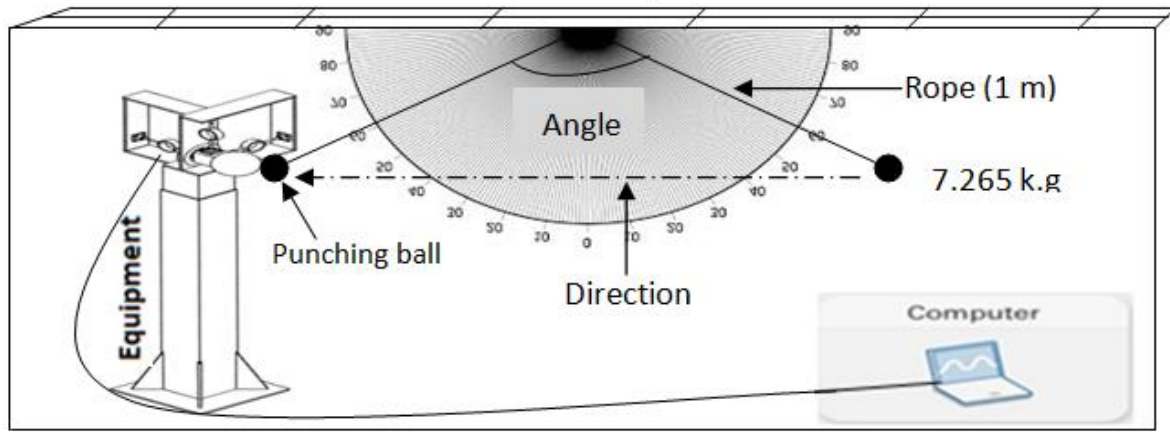

Table (1)

The scientific calibration to find the linear relationship between the power of the ball's clash and the electrical voltage of the manufactured equipment

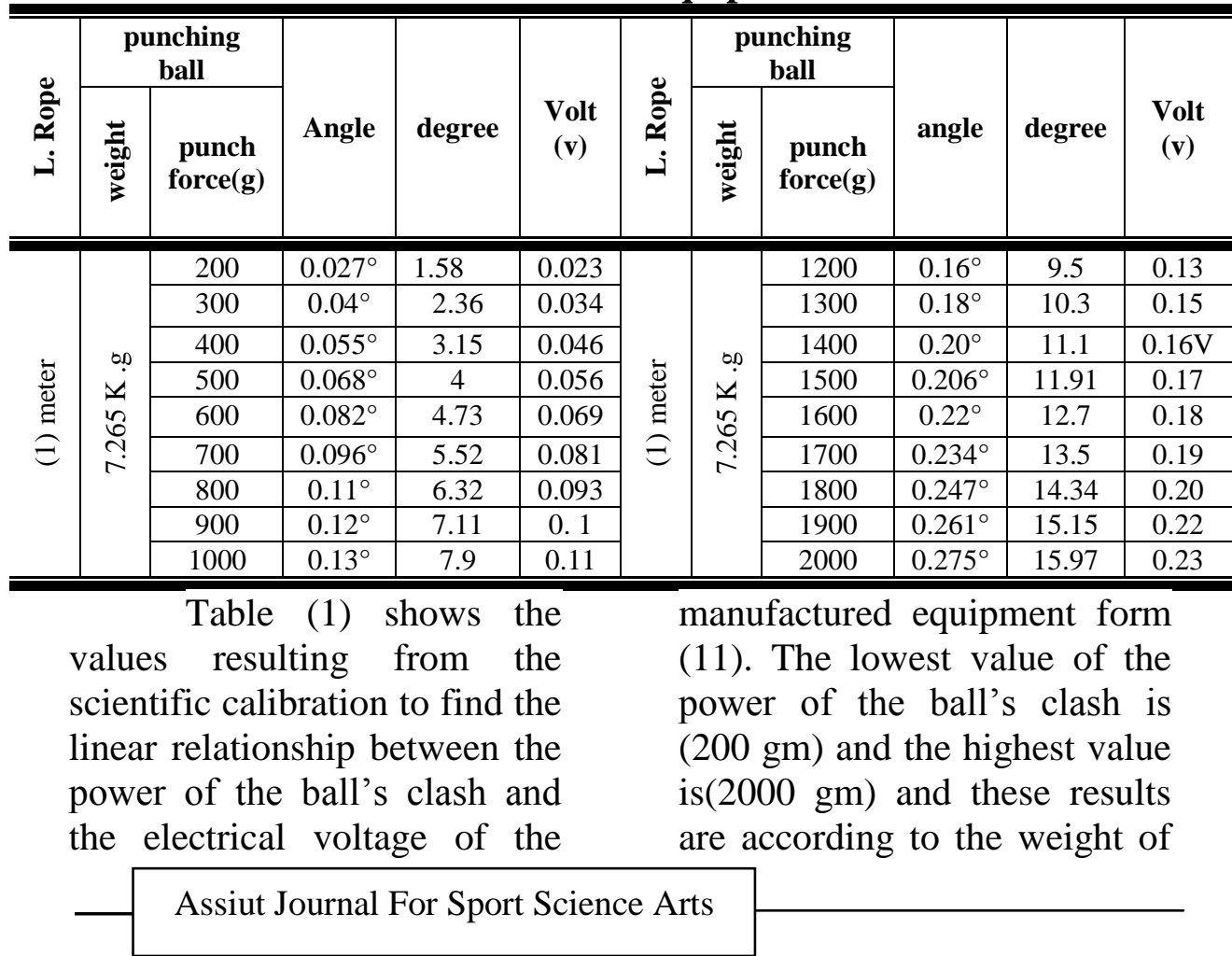


the used ball which was $(7.265$ $\mathrm{kg}$ ) and also according to the angles of the ball release which started in $\left(1.58^{\circ}\right)$ up to the maximum angel in $\left(15.97^{\circ}\right)$.
The lowest value of the electrical voltage was 0.023 voltage and the highest value was 0.023 voltage.

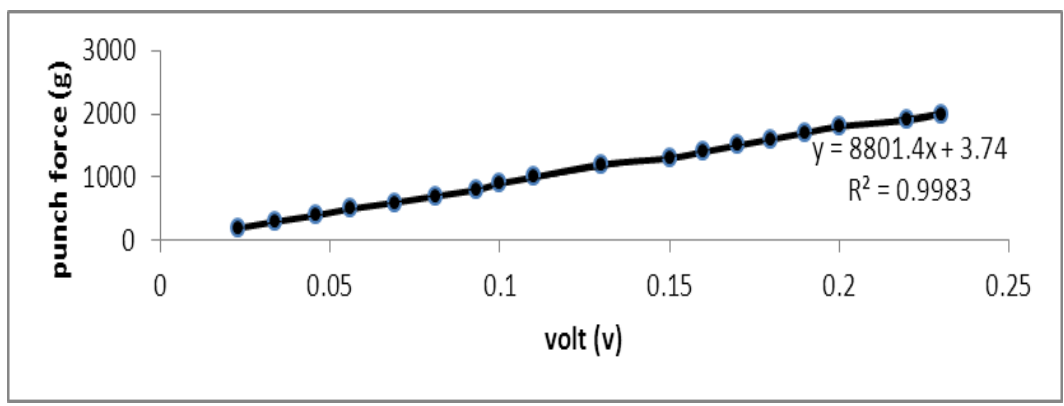

Form (11)

The linear relationship between the power of the ball's clash and the electrical voltage of the manufactured equipment. Discussing the results of the research:

First: Measurement of the three elements of the mechanical force of the hook punch in the light of geometric design:

The researcher canthrough the geometric design and the different implementations in various times- measure the power of the side punch in the head and the manufactured device shows satisfying results adequate to the technical features of the side punch as in (form 12) which shows us the geometric design characterize by the freedom of movement during the performance of the hook punch as there are not wired connections between the boxer who make the test and the equipment. form 1,2 also show results of measurements of the hook punch's power to the different types of weight (light, average, above average, heavy, super heavy). 


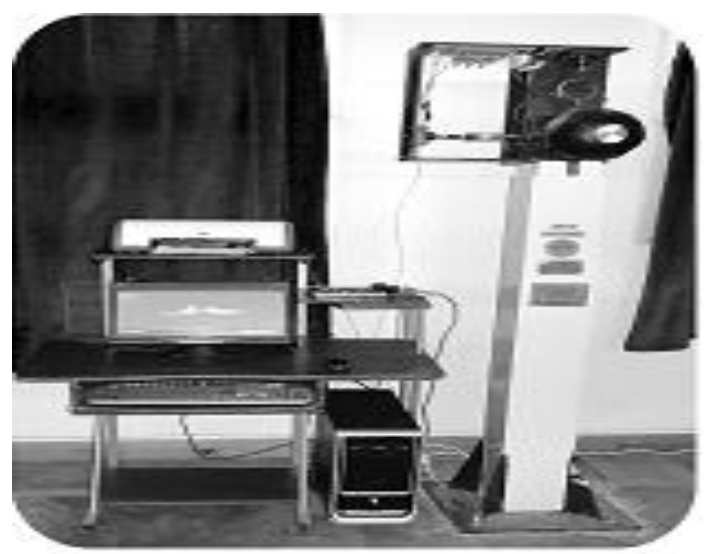

Form (12)

Punch's force measurement equipment

Second: Capturing the electrical signal wireless and converting it to legible digital values:

The research can

answer the second question as he can manufacture aequipment has the ability to capture the electrical signal through the used sensors which are fixed above the loops (Load cell) in the places of the highest values of forces (form 13) as the analog signals transferred to the technique of the data causation which convert these electric analog signals to digital values which can be read on the interface of the program in the computer to make it easy to the trainer and to introduce the required feedback.

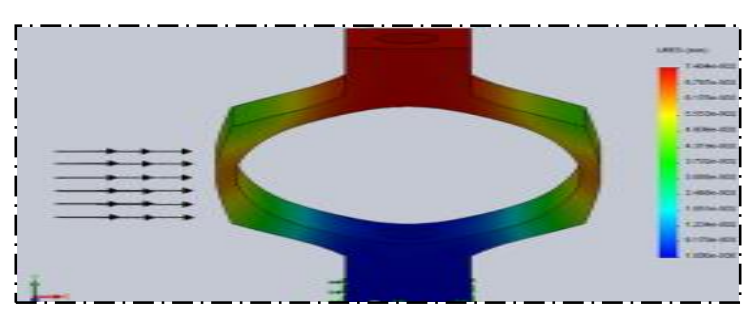

Form (13)

the places of the highest values of forces

Third: indication of the statistical differences between the averages of the three attempts of each player in the values of the hook punch's power. 
After the researcher can determine the values of the hook punch's power of the different types of weights of five boxers through the manufactured equipment, he made the first statistical and

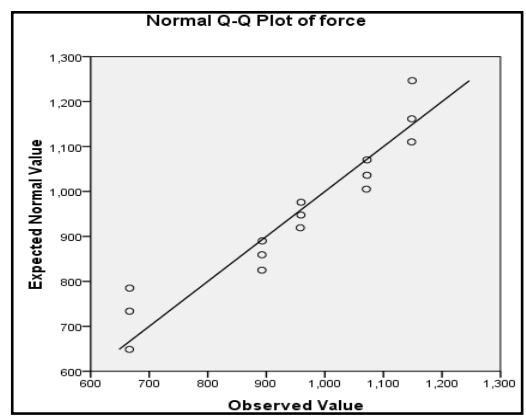

Form $(14,15)$ clarify the shape of the natural distribution of the values and their proximity to the straight line as the value of standard deviation of these values is (171.06) and this is an evidence to the equinoctial of the values and also the credibility of the manufactured

\section{Table (2)}

Indication of the statistical differences between the averages of the three attempts of each player in the values of the hook punch's power.

\begin{tabular}{|c|c|c|c|c|c|c|c|c|}
\hline \multirow{3}{*}{$\mathrm{N}$} & \multirow{3}{*}{$\begin{array}{c}\text { Weight } \\
(\mathrm{k} . \mathrm{g})\end{array}$} & \multirow{3}{*}{$\begin{array}{l}\text { Weight } \\
\text { category }\end{array}$} & \multirow{2}{*}{\multicolumn{3}{|c|}{$\begin{array}{c}\text { Punch force (values) } \\
\text { Tray }\end{array}$}} & \multirow{3}{*}{$\begin{array}{c}\text { average } \\
\text { force }\end{array}$} & \multirow{3}{*}{$\begin{array}{c}\text { Std } \\
\text { Deviation. }\end{array}$} & \multirow{3}{*}{$\operatorname{Pr} . F$} \\
\hline & & & & & & & & \\
\hline & & & $\mathrm{A}(\mathrm{N})$ & $\mathrm{B}(\mathrm{N})$ & $\mathrm{C}(\mathrm{N})$ & & & \\
\hline 1 & 56 & Lightweight & 666.6 & 676.3 & 669.4 & 670.7 & 4.99 & \multirow{5}{*}{0.1551} \\
\hline 2 & 69 & Medium weight & 900.5 & 898.6 & 893.08 & 897.4 & 3.85 & \\
\hline 3 & 81 & Above medium & 954.3 & 969.1 & 968.1 & 963.8 & 8.27 & \\
\hline 4 & 91 & Heavyweight & 1070.9 & 1082.0 & 1076.9 & 1076.6 & 5.55 & \\
\hline 5 & 107 & above heavy & 1148.4 & 1138.2 & 1159.2 & 1148.6 & 1.05 & \\
\hline
\end{tabular}

descriptive handling aiming to know if these values are submitting to the natural distribution under the curve and the absence of any dispersion in the indication of standard deviation.

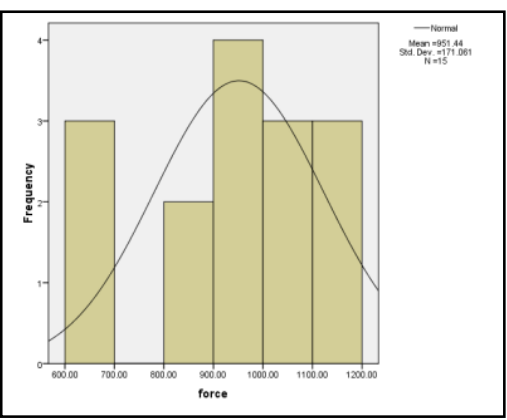

device which indeed achieve its function and so it can be used in theexperiments of measurement the side punch's power in the boxing sport. The comparisons will made by the use of (F) test because of the natural distribution of the values as we referred in the previous form. 
Table (2) clarify the arithmetic average and standard deviation to the values of hook punch's power of the three attempts of every player as the standard deviation of the weights ranges from (1.05: 8.27) and there are not significant differences between the results of the three attempts of every player in the quantity of the hook punch's force.
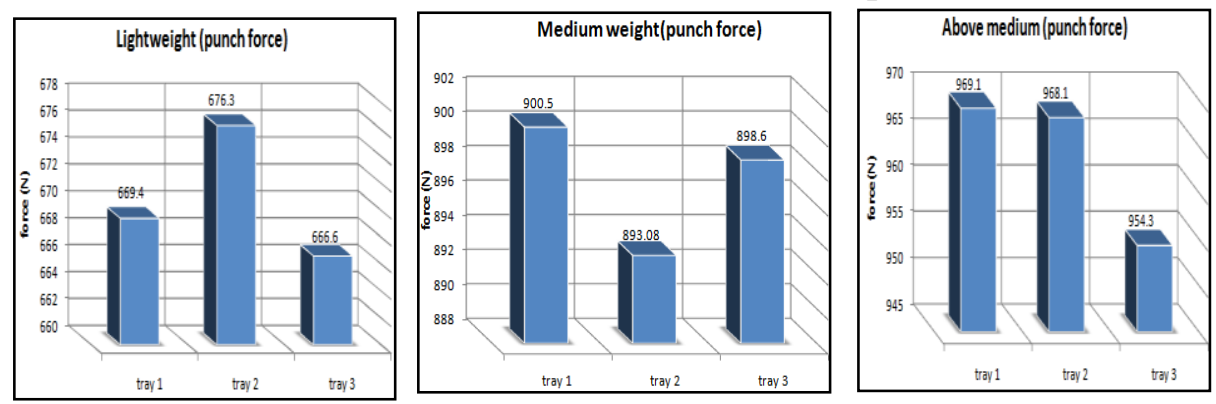

form (16) form (17) form (18)

Forms (16, 17, 18, 19, 20) clarify the values of the hook punch's power of the various weights which show the absence of any clear statistical differences between the player an himself in the
Form (19) form (20)

three attempts when the boxer was asked to perform the punch with the most power he had, and this is a clear evidence for credibility of the manufactured equipment by the researcher.

Fourth: Results of the hook punch's power between the different weight types:

Table (3)

Indication of the statistical differences between the averages of the three attempts of each player in the values of the side punch's power.

\begin{tabular}{c|c|c|c|c|c|c}
\hline \hline $\mathbf{N}$ & $\begin{array}{c}\text { Weight } \\
\text { (k .g) }\end{array}$ & $\begin{array}{c}\text { Weight } \\
\text { category }\end{array}$ & $\begin{array}{c}\text { average } \\
\text { force(N) }\end{array}$ & $\begin{array}{c}\text { The } \\
\text { general } \\
\text { average }\end{array}$ & Deviation.Std & Pr .F \\
\hline \hline 1 & 56 & Lightweight & 670.7 & & & \\
\hline 2 & 69 & Medium weight & 897.4 & & & \multirow{2}{*}{0.0001} \\
\hline 3 & 81 & Above medium & 963.8 & \multirow{2}{*}{$951.4(\mathrm{~N})$} & 171.06 & \\
\hline 4 & 91 & Heavyweight & 1076.6 & & & \\
\hline 5 & 107 & above heavy & 1148.6 & & & \\
\hline \hline
\end{tabular}


Table 3 and form (21) clarify the arithmetic average and standard deviation to the values of side punch's power of the three attempts of every player as the standard deviation of the weights reached to (171.06). There are also significant differences between the various types of weight in the quantity of the hook punch's force more than these differences between the player and himself which reached to (0.0001) and this is clear evidence that the researcher has the ability to determine the measured differences between the various types of weight in accordance to the difference between mass of the weight types.

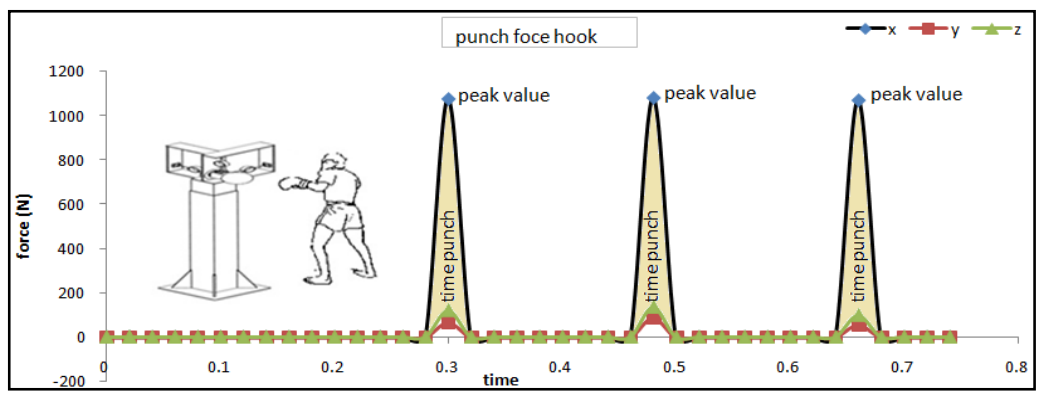

\section{The Research conclusions:}

According to the target of the research and in the light of the questions and the used method, the researcher can make the following:

- Measurement

the strength of the punch with attention to the technical features of the hook punch.

- The researcher can capture the electrical signal using the sensors which ensure the absence of any external disruption to the signal coming from sensors and amplifier to the unit which convert analog signal to a legible value.

- Relevance of the equipment to the trainer especially the absence of any external wired connections.

- Measurement of the time from the less point of the hook punch's power to the highest point.

- Sensitivity of the used sensors to start from the lowest value $(200 \mathrm{gm})$ to the highest value $(400 \mathrm{~kg})$.

- $\quad$ Easy interaction with scholars through an efficient 
design of the program's interfaces and saving data.

- $\quad$ The cheap financial cost compared to the current system.

\section{Research Recommendations:}

- Expansion the using of the manufactured device which was built on scientific and geometric basis and provide us with an immediate evaluation about the hook punch's power which enable the coach to introduce the required feedback as the

- Power is a very important thing in evaluating the technical performance of the punch.

- It is very important to develop the current equipment in other researches with higher advantages to upgrade the level of the technical performance of all the Egyptians boxers

\section{References:}

First: Arabic References:

\section{1- Adel abd- Elbasirali:}

"Biomechanics and integration of theory and practice in the field of sports" Cairo,Book publishing center,1998.

2- AudaiGaseb Hassan "The bio-mechanic Analysis of the sports skills" Iraq, 2006.

3- Mohammed Yosuf Elsheikh: Vital Mechanics and Its Applications" Alexandria 1986.

\section{4- Mokhtar Salem}

Mohammed: "The Boxing Craft" Elma'aref Institution, Beiruit, Lebanon, 1990.

\section{Second: English References:}

1- SeyyedKhandani:"Engi neering designprocess"2005.

Third: Websites from the internet:

6- $\quad$ http://www.eulc.edu.eg/ eulc_v5/Libraries/Thesis/Brow seThesisPages.

7-http://www.hazemsakeek. org/Physics_Lectures/Mechani cs/includegp1lectuers_1. 